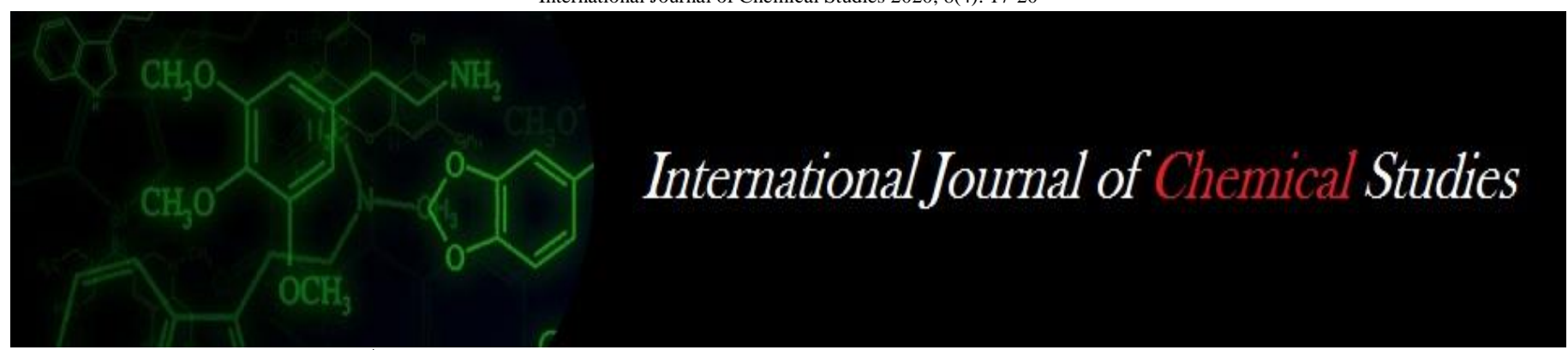

P-ISSN: 2349-8528

E-ISSN: 2321-4902

www.chemijournal.com

IJCS 2020; 8(4): 17-20

(C) 2020 IJCS

Received: 26-04-2020

Accepted: 07-06-2020

\section{Ivwurie W}

Department of Chemistry,

Federal University of Petroleum Resources, PMB 1221, Effurun,

Delta State, Nigeria

Ediale P

Department of Chemistry,

Federal University of Petroleum

Resources, PMB 1221, Effurun,

Delta State, Nigeria
Corresponding Author:

Ivwurie W

Department of Chemistry,

Federal University of Petroleum

Resources, PMB 1221, Effurun,

Delta State, Nigeria

\section{The production of biodiesel from sewage sludge via soxtherm extraction using chloroform and methanol in ratio 2:1 as the organic solvent and transesterification reaction}

\section{Ivwurie $W$ and Ediale $P$}

DOI: https://doi.org/10.22271/chemi.2020.v8.i4a.10252

Abstract

Soxtherm apparatus was used to extract oil/lipids from a primary sewage sludge using chloroform and methanol $(2: 1)$ as the organic solvent. Biodiesel was produced from the extracted lipid via transesterification process. The physiochemical properties of the extracted lipid and the biodiesel were determined. A percentage yield of $26.42 \%$ was obtained for lipids extraction which proved that the solvent mixture of chloroform and methanol (2:1) gave a reasonably higher yield than using a single solvent for lipid extraction. For biodiesel production from the extracted lipid, a percentage yield of $85.12 \%$ was obtained. The results gotten from analysis carried out on both lipids and biodiesel were consistent with available literature and suggests that as much as primary sewage sludge is a good feedstock for biodiesel production, using chloroform and methanol (2:1) as an extracting solvent for lipids would improve lipid yield as well as the biodiesel quantity.

Keywords: biodiesel, lipid, transesterification, sewage sludge, soxtherm

\section{Introduction}

As the world population and industrialization continues to grow, humanity will consistently consume more energy. As we consider the future, the expansion of the global economy, the development of new technologies, new industry and an increase in the world's population, it becomes obvious there will be an increase in the demand for world energy ${ }^{[1]}$. According to the International Energy Agency, the world will need 37\% more energy in 2040 than today [2]. Therefore, we are entering a phase of very high energy consumption growth. In addition, the environmental problems associated with excessive usage of fossil fuels such as air pollution, greenhouse gas emissions (GHG), and global warming, consequently limits the utilization of these sources in the future.

The high energy demand in the industrialized world as well as in the domestic sector; and pollution problems caused due to the widespread use of fossil fuels, make it increasingly necessary to develop the renewable energy sources of limitless duration with smaller environmental impact than the traditional one ${ }^{[3]}$. This has stimulated recent interest in alternative sources for petroleum based fuels, that must be technically feasible, economically competitive, environmentally acceptable, and readily available ${ }^{[4]}$.

Biofuels are a type of fuel derived from organic matter (broadly described as biomass) produced by living organisms i.e. plants and animals. According to the International Energy Agency (IEA), biofuels have the potential to meet more than a quarter of world demand for transportation fuels by $2050^{[5]}$. Biofuels are fuels based on renewable biomass. Amongst the biofuels, including biogas, bioethanol and biodiesel, the greatest demand is for biodiesel, which is considered as an alternative to petroleum-based fuel.

Biodiesel mainly consists of fatty acid methyl esters (FAMEs) obtained by reacting vegetable oils and animal fats with an alcohol in the presence of a catalyst. Biodiesel is renewable, less toxic and has low environmental impact, when compared to petroleum-based diesel. The competitive potential of biodiesel is currently limited by the price of the common lipid feedstock, which constitutes $70-85 \%$ of the overall biodiesel production cost, thus strongly 
influencing the final price of this biofuel and raising the concerns of food shortage versus fuel crisis ${ }^{[6]}$.

However, municipal sewage sludge from wastewater treatment plants (WWTPs) is gaining more attention nowadays as a lipid feedstock for the production of biodiesel; as the dry sludge can contain up to $30 \mathrm{wt} \%$ of lipids ${ }^{[7]}$. In fact, sewage sludge is a waste that needs specific treatment before disposal and represents a major cost in the WWTP operation. In addition, the WWTPs annually produces higher amounts of sludge due to the expansion of urbanized and industrialized areas. Therefore, the sewage sludge can be envisaged as a relatively cheap, readily available, and abundant feedstock, which can make the biodiesel production profitable. Furthermore, it is one possible alternative to take advantage of the excess sludge, reusing it as a source of lipid for the production of biodiesel, consequently lowering the waste water treatment plant operation cost ${ }^{[8]}$.

Sewage sludge is the waste formed during treatment of waste water. These waste water treatment plant produces primary and secondary sludge. Lipids could yield an unexploited source of cheap and readily available feedstock for biodiesel production ${ }^{[1]}$.

Lipids are generally soluble in organic solvents, so we can use solvents to extract lipids from sludge. Some solvents such as ethanol, ethyl ether, petroleum ether, hexane and methanol have been used for extraction of lipids. In which hexane and methanol are widely used ${ }^{[9]}$. Transesterification, also called alcoholysis, is the displacement of alcohol from an ester by another alcohol in a process similar to hydrolysis. This process has been widely used to reduce the viscosity of triglycerides, thereby enhancing the physical properties of renewable fuels to improve engine performance.

This research is basically focused on how best the production of biodiesel can be carried out from sewage sludge. Owing to the fact that over the years, biodiesel has been produced from common sources such as vegetable oils, animal fats, plant seeds, more recently sewage sludge which has become potential feedstock, given that humans faeces are readily available, and other lipid-containing wastes. This research covers the possibility of extracting the lipid from the sewage sludge using chloroform and methanol $(2: 1)$ as the organic solvent and how biodiesel can be produced from the extracted lipid via transesterification reaction.

\section{Materials and methods \\ Sample collection and preparation}

The sample collection for primary sewage sludge was carried out in a sewage sludge treatment plant in Lagos State, Nigeria. The thick sludge was collected from the bottom of the settling tank into a 10-liter bucket and covered with a lid. After the sample was sun dried for 7 days and then air dried for another 3 days, the dried primary sludge was reduced in particles by using a pestle and mortar, where it was pounded until the big particles of the dried sewage sludge reduced to granules. The particle size was further reduced using an industrial blender to undergo a highly efficient extraction.

\section{Extraction of the lipid}

The Soxtherm extractor was used in extracting the lipid (oil) from the blended sewage sludge. The sample was put into the thimbles and then inserted into the extraction beakers. About $140 \mathrm{ml}$ of the solvent mixture was added to the extraction beakers which were pushed against the rear limit stop of the hot plate of the extractor in other to achieve correct positioning. The Soxtherm extractor was then programmed to heat at $150^{\circ} \mathrm{C}$ which is a boiling point higher than that of the solvent being used and the lipid was extracted

\section{Physiochemical analysis of the oil}

The extracted lipid was then analyzed to determine its percentage yield, density, acid value, free fatty acid and other properties.

\section{Transesterification}

The oil was transesterified by preparing a methoxide solution which was carried out by dissolving $1 \% \mathrm{NaOH}$ of the weight in mass of the lipid in $20 \%$ methanol of the weight in mass of the lipid and was heated at a steady temperature of $60^{\circ} \mathrm{C}$ monitored by a thermometer for an hour with constant stirring of the mixture using a hot plate magnetic stirrer. After the reaction process, the mixture was transferred into a separatory funnel and was allowed to settle and cooled while the separation of the two phase layer took place to separate into the methyl ester phase and glycerin phase as the upper and lower phase respectively ${ }^{[10]}$.

Glycerol was removed by means of a separating funnel, and the remaining ester layer was washed four times with distilled warm water to remove soap, residual alcohol, catalyst, and unreacted tri, di-, and monoglycerides. The number of washing processes was not increased because increasing the washing beyond four times does not have further benefit. The biodiesel washing sometimes leaves the biodiesel looking a bit cloudy. This means there's still a little water in it. It was heated slowly to $100^{\circ} \mathrm{C}$ and held there until all moisture present was evaporated. The biodiesel was then kept in a glass bottle.

\section{Physiochemical characterization of biodiesel}

After the separation and washing process, characterization of the biodiesel was carried out to determine its $\mathrm{pH}$, cetane number, viscosity, pour point, flash point and other important physiochemical characterizations.

\section{Results and discussion}

The results for the determination of the physiochemical properties of extracted lipid (oil) from the sewage sludge and the biodiesel produced are presented in Tables 1 and 3, while the ASTM specifications is presented in table 2.

The oil extracted gave a brownish black colour and a pungent smell. This is quite different from the regular the colours reported for other biodiesel produced from different sources like Garlic which is light yellow ${ }^{[11]}$. This variation could be because of the primary sewage sludge used as a feedstock which possesses same characteristic properties. Palm Kernel oil, unrefined oil soybean oils and Jatrophacurcas oil gave golden yellow colour, while palm oil and refined soybean gave red and light yellow colours, respectively ${ }^{[12]}$.

The percentage yield of the lipid extracted was $26.42 \%$ using a mixture of Chloroform and Methanol in ratio 2:1 as the extracting solvent. Although, the percentage yield is low, the availability of human faeces in good quantity makes the use of lipids from this source a viable alternative ${ }^{[8]}$.

\section{The acid value of oil is used as a measure of quality}

The density of oil is the ratio of the mass or weight of the oil to the volume of the oil $(\mathrm{ml})$. Specific gravity which is the ratio of the density of a respective substance to the density of water at $4^{\circ} \mathrm{C}$. For the extracted oil, the density and specific gravity of the extracted oil was found to be $0.912 \mathrm{~g} / \mathrm{ml}$ and 
0.912 respectively. This value is slightly lower than those reported for unrefined soybean and palm oil ${ }^{[12]}$.

Viscosity is a measure of internal friction. Kinematic viscosity is the resistance of the oil to flow and shear due to gravity. The viscosity and kinematic viscosity of the extracted oil was $39.91 \mathrm{~mm}^{2} / \mathrm{Sec}$ and $42.30 \mathrm{~mm}^{2} / \mathrm{Sec}$ respectively. This result is within the value suitable for biodiesel production.

The acid value of the oil was $6.35 \mathrm{mg} \mathrm{KOH} / \mathrm{g}$ and the Free Fatty Acid (FFA) was 3.18\%. It is reported that oil with high free fatty acid can decrease the transesterification yield, inhibiting the formation of methoxides by neutralization of part of the catalyst present; and producing soaps within the reaction medium ${ }^{[13]}$. Therefore, the free fatty acid value obtained suggests that the oil will be good for the production of biodiesel.

The saponification value indicates the ability of the oil to make soap. High saponification value indicates that oils are normal triglycerides and will be useful in production of liquid soap and shampoo industries. The saponification value was found to be $195.10 \mathrm{mg} \mathrm{KOH} / \mathrm{g}$ which is quite high. This value is lower than those of palm kernel oil, Jatropha curcas oil, with values of $247.0 \mathrm{mgKOH} / \mathrm{g}$ and $202.6 \mathrm{mg} \mathrm{KOH} / \mathrm{g}$, respectively ${ }^{[12]}$.

The iodine value (IV) is a measurement of the unsaturation of fats and oils. The iodine value of the oil was $59.8 \mathrm{mg} / \mathrm{g}$ which was quite low. The generally low IVs imply that they are all non-drying oils. Also it suggests that the oil contains mostly saturated triglyceride molecules. Low-IV oils have higher cetane values and are more efficient fuels than high-IV oils, but they also have higher melting points and are usually solid at room-temperature. Biodiesel made from low-IV oils also has a higher melting point and might only be suitable for use as summer fuel. High-IV oils have lower melting points and make better cold-weather biodiesel, but with high-IV oils there is more risk of the biodiesel oxidising and polymerising (drying) into a tough, insoluble plastic-like solid. This can lead to the formation of deposits or to deterioration of the lubricating engine ${ }^{[14]}$.

Table 1: Physicochemical properties of the extracted oil

\begin{tabular}{|c|c|}
\hline Parameters & Property \\
\hline Colour & Dark brown \\
\hline Smell & Pungent \\
\hline Percentage yield (\%) & 26.42 \\
\hline Density $(\mathrm{g} / \mathrm{ml})$ & 0.912 \\
\hline Specific gravity & 0.912 \\
\hline Acid value (mg KOH/g) & 6.35 \\
\hline Free Fatty Acid value (\%) & 3.18 \\
\hline Viscosity $\left(\mathrm{mm}^{2} / \mathrm{sec}\right)$ & 39.91 \\
\hline Kinematic viscosity $\left(\mathrm{mm}^{2} / \mathrm{sec}\right)$ & 43.30 \\
\hline Saponification Value $(\mathrm{mg} \mathrm{KOH} / \mathrm{g})$ & 195.10 \\
\hline Iodine value $\left(\mathrm{g} \mathrm{I}_{2} / 100 \mathrm{~g}\right)$ & 59.8 \\
\hline
\end{tabular}

Table 2: Biodiesel specifications according to American Standard and Testing Materials (ASTM)

\begin{tabular}{|c|c|c|}
\hline Properties & ASTM Method & Limits \\
\hline Percentage yield $(\%)$ & - & - \\
\hline $\mathrm{pH}$ & - & - \\
\hline Density, $15^{\circ} \mathrm{C}\left(\mathrm{g} / \mathrm{cm}^{3}\right)$ & $\mathrm{D} 1298$ & $0.830-0.900$ \\
\hline Specific gravity & $\mathrm{D} 1298 / 4052$ & $0.900 \mathrm{max}$ \\
\hline Acid value $(\mathrm{mg} \mathrm{KOH} / \mathrm{g})$ & $\mathrm{D} 664$ & $0.80 \mathrm{max}$ \\
\hline Kinematic viscosity $\left(\mathrm{mm}^{2} / \mathrm{sec}\right)$ & $\mathrm{D} 445$ & $1.9-6.0$ \\
\hline Sulphated ash content $(\% \mathrm{~m} / \mathrm{m})$ & $\mathrm{D} 874$ & $0.020 \mathrm{max}$ \\
\hline Flash point $\left({ }^{\circ} \mathrm{C}\right)$ & $\mathrm{D} 93$ & 130 min \\
\hline Cloud point $\left({ }^{\circ} \mathrm{C}\right)$ & $\mathrm{D} 2500$ & Report to customer \\
\hline Pour point $\left({ }^{\circ} \mathrm{C}\right)$ & $\mathrm{D} 97$ & - \\
\hline Copper strip corrosion & D130 & No. 3 max \\
\hline Cetane number & D613 & 47 min \\
\hline
\end{tabular}

Table 3: Physiochemical analysis values of biodiesel produced

\begin{tabular}{|c|c|}
\hline Parameters & Values \\
\hline Percentage yield $(\%)$ & 85.12 \\
\hline $\mathrm{Ph}$ & 9.51 \\
\hline Density, $15^{\circ} \mathrm{C}\left(\mathrm{g} / \mathrm{cm}^{3}\right)$ & 0.871 \\
\hline Specific gravity & 0.871 \\
\hline Acid value $(\mathrm{mg} \mathrm{KOH} / \mathrm{g})$ & 0.24 \\
\hline Kinematic viscosity $\left(\mathrm{mm}^{2} / \mathrm{sec}\right)$ & 4.51 \\
\hline Sulphated ash content $(\% \mathrm{~m} / \mathrm{m})$ & 0.030 \\
\hline Flash point $\left({ }^{\circ} \mathrm{C}\right)$ & 103 \\
\hline Cloud point $\left({ }^{\circ} \mathrm{C}\right)$ & 3 \\
\hline Pour point $\left({ }^{\circ} \mathrm{C}\right)$ & -3 \\
\hline Copper strip corrosion & No. $1 \mathrm{a}$ \\
\hline Cetane number & 54.8 \\
\hline
\end{tabular}

The percentage yield of biodiesel was found to be $85.12 \%$. This value is reasonably promising for commercial production purpose.

The $\mathrm{pH}$ value of the biodiesel was 9.51 , while the density at $15^{\circ} \mathrm{C}$ and specific gravity was $0.871 \mathrm{~g} / \mathrm{cm}^{3}$ and 0.871 respectively. This value obtained falls within the limit specified for biodiesel fuels by biodiesel standard with ASTM D1298/4052 and D1298 respectively having, the range of $0.86-0.90 \mathrm{~g} / \mathrm{cm}^{3}$ and $0.90 \max$.

The acid value measures the content of free fatty acids in biodiesel; and the presence of free fatty acids influences fuel aging due to hydrolytic cleavage of ester bond. The acid value analyses carried out on the biodiesel was calculated to be $0.24 \mathrm{mKOH} / \mathrm{g}$ and falls in the range of the ASTM standard. This shows that the acid value is low and therefore the biodiesel has good storage capability compared to the acid values of palm kernel oil methyl ester and refined soybean oil methyl ester with slightly higher values of 0.37 and $0.36^{[12]}$.

The kinematic viscosity of the biodiesel was $4.51 \mathrm{~mm}^{2} / \mathrm{Sec}$, which is consistent with the conventional biodiesel standard; and slightly higher than the petroleum diesel (Biodiesel Handling and use). The $40^{\circ} \mathrm{C}$ reference point is a parameter required by the biodiesel and petroleum diesel standards. This value obtained here suggests that the biodiesel satisfies the fluidity requirement of an alternative biodiesel and can reduce wear and tear in a biodiesel engine. Viscosity is closely related to the fatty acids composition of a given biodiesel sample. It increases with increasing length of fatty acid chain [15].

Other physicochemical parameters listed in table 3 are consistent with standards listed in table 2.

\section{Conclusion}

From the results of this study, it can be deduced that the primary sewage sludge is a promising feedstock for biodiesel production. The main advantage in biodiesel usage is attributed to lesser exhaust emissions in terms of carbon monoxide, hydrocarbons and particulate matter. The biodiesel can also be used as a blend to supplement the petroleum derived diesel.

From the laboratory scale production and characterization of the methyl ester of sewage sludge biodiesel studied, it may also be concluded that the lipid yield by using solvent mixtures like chloroform and methanol using soxtherm extraction method was higher than using just a single solvent for extraction.

This work indicates that sewage sludge is an economically viable feedstock for production of biodiesel. And most especially, the results show that using solvent mixture to extract lipid from the dried sewage sludge for biodiesel production can improve the yield. 


\section{Reference}

1. Olkiewicz M, Fortuny A, Stüber F, Fabregat A, Font J, Bengoa C. Evaluation of different sludges from WWTP as a potential source for biodiesel production. Procedia Eng. 2012; 42:634-64.

2. International Energy Agency. Key World Energy Statistics 2014, IEA, Paris Cedex 15, France, 2014, 82.

3. Bharathi P, Karthiga R, Shamli M, Vivetha K, Subathra M. Extraction of Lipids from Municipal Sewage Sludge for Production of Biodiesel via Transesterfication process. International Journal of Pharma and Bio Sciences. 2014; 5(4):B132-B141.

4. Meher LC, Sagar DV, Naik SN. Technical aspects of biodiesel production by transesterification. Renewable and Subtainable Energy Reviews, 2004, 1-21.

5. Meghan G. IEA says biofuels can displace $27 \%$ of transportation fuels by 2050 . Platts @ http://www.platts.com/RSSFeedDetailedNews/RSSFee d/Oil/6017103,2001.

6. Kwon EE, Kim S, Jeon YJ, Yi H. Biodiesel production from sewage sludge: new paradigm for mining energy from municipal hazardous material, Environ Sci. Technol. 2012; 46(18):10222-10228.

7. Pastore C, Lopez A, Lotito V, Mascolo G. Biodiesel from dewatered waste water sludge: A two-step process for a more advantageous production. Chemosphere. 2013; 92:667-673.

8. Dufreche S, Hernandez R, French T, Sparks D, Zappi M, Alley E. Extraction of lipids from municipal wastewater plant microorganisms for production of biodiesel. J Am Oil Chem Soc. 2007; 84(2):181-187.

9. Fenfen Z, Zhao L, Zhang Z, Jiang H. Procedia Environmental Sciences. 2012; 16:352-356.

10. Gerpen JV, Shanks B, Pruszko R, Clements D, Knothe G. Biodiesel Production Technology. National Renewable Energy Laboratory. Colorado, 2004, 105.

11. Hassan LG, Sani NA. Comparative Studies on the Physico-chemical Properties of Bottle Gourd Lageneriasiceraria seeds oils Extracted by two methods. Nigeria Journal of Basic and Applied Sciences. 2007; 15(1), (2):50-51.

12. Ankapong E. The influence of physiochemical characteristics of vegetable oils on the quality of Biodiesel produced from palm oil, palm kernel oil, refined soyabean oil, unrefined soyabean oil and jatrophacurcasoil. MSc. Thesis, Kwame Nkrumah University of Science and Technology, Kumasi, 2010.

13. Barabás, I. and Todoruţ, I. Biodiesel Quality, Standards and Properties, Biodiesel- Quality, Emissions and ByProducts, Dr. Gisela Montero (Ed.), ISBN: 978-953-307784-0, InTech, Available from: http://www.intechopen.com/books/biodiesel-qualityemissions-and-by-products/biodiesel-quality-standardsand-properties, 2011.

14. Mittelbach M. Diesel fuel derived from vegetable oils: VI. Specifications and quality control of biodiesel. Bioresour Technol.1996; 56(1): 7-11.

15. Odiganma D. Production of Biodiesel from sewage sludge, a constituent of human excrement using nHexane as the organic solvent. BSc. Thesis. Department of Chemistry. Federal University of Petroleum Resources, Effurun, 2016. 